\title{
Language Development: The Effect of Aquatic and On-Land Motor Interventions
}

\author{
Ronit Ram-Tsur ${ }^{1}$, Michal Nissim ${ }^{1}$, Michal Zion ${ }^{1}$, Tal Dotan Ben-Soussan ${ }^{2,3}$, Zemira Mevarech ${ }^{1}$ \\ ${ }^{1}$ School of Education, Bar-Ilan University, Ramat-Gan, Israel \\ ${ }^{2}$ The Gonda (Goldschmied) Multidisiplinary Brain Research Center, Bar-Ilan University, Ramat-Gan, Israel \\ ${ }^{3}$ Research Institute for Neuroscience, Education and Didactics, Patrizio Paoletti Foundation \\ for Development and Communication, Assisi (PG), Italy \\ Email: ronitram@netvision.net.il
}

Received July 2013

\begin{abstract}
The aim of the current preliminary research was to examine the relationship between aquatic motor activities and language abilities. Our hypothesis suggests that changing the environment to water may improve motor and linguistic abilities. The study included 94 children between the ages of four and six. Thirty-one children who participated in aquatic motor activities were compared to 41 children who participated in on-land motor activities and to 21 children who participated in non-motor activities. Developmental-functionality tests, including gross and fine motor, time estimation and language tests, were used to diagnose participants' abilities before and after six months of intervention. We found significant improvement in gross motor, fine motor and time estimation abilities for the aquatic motor activities group. Moreover, improvement in gross motor and time estimation abilities moderated the association between aquatic motor activities and children's naming ability, suggesting the positive effect of aquatic motor activities on language abilities. Based on these novel findings, child-development professionals can have a better understanding of relation between language abilities and motor abilities, possibly leading to an improvement of intervention methods with early-childhood patients. Early childhood intervention could aid in reducing primary differences between children in motor abilities, and especially in motor-development disorders, which in turn are thought to lead to additional learning disabilities.
\end{abstract}

Keywords: Early Childhood Intervention; Physical Activity; Aquatic Environment; Language; Time Estimation

\section{Introduction}

Over the years, many studies have shown that physical activity has mental, cognitive and physical benefits (Cragg \& Cameron, 2006; Ben-Soussan, Glicksohn, Goldstein, BerkovichOhana, \& Donchin, 2013; Warburton, Nicol, \& Bredin, 2006). Since there is high neuroplasticity in early childhood (Hannaford, 2005) and the early years are the most cost-effective time to intervene (Heckman, Stixrud, \& Urzua, 2006), we wanted to examine the effects of physical activity in children. Appropriate motor performance at the ages 4-6 is a prerequisite for learning; deficient motor performance is thought to be a sign of possible academic problems in the future (Losse et al., 1991). Although every child has a unique developmental pattern, development is influenced by the interaction between life experiences and the environment in which these occur. For example, according to the dynamic-system theory, the interaction between the individuals, the purpose of the task and the environmental conditions contribute to the child's development (Smith \& Thelen, 2003). It is thus theoretically possible that changing the training environment from non-aquatic to aquatic, may enhance the child's capabilities, improve existing skills and/or introduce new ones. In fact, throughout history, water has been used for many purposes, including physical therapy, sport, and physical hygiene. These activities have been made possible by the advantages of water's special qualities (Becker \& Cole, 1997; Becker, 2009;
Campion, 1997). Consequently, we chose to examine the changes in language abilities following Aquatic Motor Activities (AMA) in comparison with On Land Motor Activities (OLMA) and Non Motor Activities (NMA) in children. Because of the unique qualities of water, a child can be exposed to new skills such as diving and floating, which cannot be performed on land. In addition, AMA provides multisensory stimulation combining three sensory systems: vestibular, proprioception and tactile. This multisensory stimulation may improve balance and coordination (Ahrendt, 1999; Devereux, Robertson, \& Briffa, 2005). Immersion improves balancing abilities by increasing the proprioceptive input to the immersed body and provides greater body alignment and stability. Sensory feedback is increased by promoting a sense of body awareness, as resistance to movement through water is greater than resistance through air (Roth et al., 2006). AMA also exposes the child to sensorimotor stimuli, including floating boards and sinking objects, which can be used only in an aquatic environment.

Thus, AMA during early childhood constitutes a unique platform for working on skills related to sensorimotor development, such as automatic movements and balance, which could be improved through aquatic activity by training on different depths without the interference of gravity (Campion, 1997). Moreover, sensorimotor integration may be stimulated more effectively in the aquatic environment, since the water provides three dimensions of movement: forward-backward, up-down and right-left. 
The experience of these spatial concepts depends on the particular kind of individuals' body, and how that body learns to interacts with its surroundings (Lakoff \& Johnson, 1999).

A recent study investigating the influence of water immersion on cortical activation, using functional near-infrared spectroscopy, has found that water immersion induced cortical activation in both somatosensory and motor areas. These results suggest that water immersion may enhance motor learning during the period of acquisition of motor skills (Sato et al., 2012). The results of the Zelazo \& Weiss experiment (2006) for initial five-test trials for infants aged four-, eight-, twelve- and sixteen-months were similar for kicking, arm flexion, the righting response, turning 180 degrees, and grasping the pool wall. Infants at all four ages initially displayed disorganized behaviors. The study showed that training improved all behaviors during the initial five test trials for all four age groups. The data from Zelazo'\& Weiss's experiment implies that early neuro-motor development is a bi-directional process, in which the infant's movement results in feedback from the environment, which then influences both central and peripheral nervous system development.

The integration of the sensorimotor information learned in controlling the aquatic environment is made possible by the plasticity of the nervous system, which enables it to develop a network of neural connections as a response to experiences in life. These neural groups create communication patterns which develop into neural paths, particularly after repetition. It has been observed that brain structure undergoes changing throughout life. These changes are influenced by the environment, by the individual's exposure to different stimulus, and by genetics (Blakemore \& Frith, 2005).

One of the investigated areas in the brain is the neuroplasticity of the cerebellum (Grossman et al., 2002). It has long been known that it is involved in the coordination of movements, balance and posture, visually-guided movements, and motorlearning (Stoodley \& Stein, 2011). In the last decades, evidence has indicated its importance in timing processes (Harrington \& Haaland, 1999). Studies have shown that patients with cerebellar lesions displayed poor performance in time-estimation task (Ivry, Keele, \& Diener, 1988; Ivry \& Keele, 1989; Ivry \& Diener, 1991). Several studies have shed light on additional functions of the cerebellum (Stoodley \& Stein, 2011). One study, which explored a population with reading disabilities (dyslexia), suggested that cerebellar deficits can lead to phonological and processing-speed problems. The cerebellar deficits are thought to affect articulation and working memory, due to deficits in the timing functioning which interfere with the automatization of function development. These findings have constituted the "cerebellar deficit hypothesis of dyslexia” (Nicolson, Fawcett, \& Dean, 2001). In support of this hypothesis, Specific Language Impairment (SLI) in children was found to be related to low motor performance (Hill, 2001), and impaired motor function is further evident in Developmental Language Impairment (DLI) (Webster, Majnemer, Platt, \& Shevell, 2005). Despite the above findings, the connection between motor experience, language development and cerebellum functionality is still debated. This is also probably due to the fact that there is a dearth of evidence for the comparative effects of differing environments on language development. More specifically, in addition to the scarcity of studies aimed at understanding of the possible motor aspects important for the cognitive enhancement, there have been very few researches in the field related to AMA's contribution to physiological or motor-related functioning. Consequently, the current study combined motor- and language-related research, in order to provide practical understanding of the importance of AMA. We posited a neurobiological hypothesis for the relationship between AMA and language processes. To this end, we aimed at examining three main questions:

1) Do the changes in the fine motor and time estimation abilities mediate the effect study group on the gross motor abilities?

2) Do the changes in the fine motor and time estimation abilities mediate the effect study group on the language abilities?

3) Do the changes in the gross motor abilities mediate the effect of study group on the linguistic abilities?

\section{Method}

\section{Participates and Procedure}

Study participants were recruited from a regional kindergarten-complex serving 350 children between the ages of four and six. Participants were recruited from September 1 through October 31, 2011. The research was approved by the Ministry of Education's Chief Scientist in Israel and by the Bar-Ilan University ethics committee. In order to ascertain if the child was appropriate for the current study, and which grouping best represents the child, parents of potential research participants were requested to complete a developmental and background questionnaire. Criteria for the child's eligibility included: (a) participation in only one additional extracurricular activity provided by the local community center after October 31, 2011; (b) in order to control the motivation and willingness of each subject to participate in each activity, the choice of the activity was the child's and not the parent's according to the questionnaire given to the parents; (c) there was no absence longer than one week from the kindergarten before October 31, 2011. The study further excluded children who were receiving additional therapies such as occupational, speech, or physical therapies. Onehundred and twenty-nine parents returned the questionnaire and a total of $111(86 \%)$ children were found appropriate for the current study. Testing of motor abilities, cognitive abilities and time estimation ability were conducted during personal meetings with the children prior to the activities and after six months of participation. The activity took the form of a weekly training session of 45 minutes' duration.

\section{Training Groups}

\section{Aquatic Motor Activities (AMA)}

The AMA occurred in a hydrotherapy pool (14 meters long and 5 meters wide and kept at $33^{\circ} \mathrm{C}$. The pool depth ranged from 80 centimeters to 140 centimeters). One swimming instructor accompanied five children in the water. The children learned how to control the aquatic environment in activities including standing and walking in water up to the chest, floating on the back/stomach, rolling over from stomach to back (and vice versa) while kicking with legs and moving the hands, and diving. Thirty-three children were in this group at the beginning; two left the activity during the experiment. Therefore, the group included 31 children.

\section{On-Land Motor Activities (OLMA)}

The second intervention group included 45 children who par- 
ticipated in OLMA (basketball, football, judo, general gymnastic or ballet). Four left the activity during the experiment. Therefore, the OLMA group included 41 children.

\section{Non-Motor Activities (NMA)}

The third intervention group consisted of 33 children participating in NMA (chess, drama or art). Four left the activity and six added another motor activity during the study and so were left out of the sample. Another child had medical problems and was also not included in the sample. Therefore, the NMA group included 22 children.

\section{Tasks}

The cognitive protocol included the following test:

The Raven's coloured progressive matrices were used to estimate differences between study groups at baseline. This is a well-known assessment battery of nonverbal intelligence using the ability of matching appropriate colors and patterns. The outcome is the number of correct answers and the total time taken (Raven, 1965).

The language protocol included the following tests (for a detailed explanation about punctuation in Hebrew, see (Ram-Tsur, Faust, \& Zivotofsky, 2008):

Semantic Fluency test (Kave, 2006) which measures ability to retrieve information from semantic memory. The child has to name as many words in a category as he/she could within one minute. Semantic fluency was measured in the categories of "animals" and "food". These are categories used in most studies on semantic fluency (Hurks et al., 2006; Riva, Nichelli, \& Devoti, 2000). The outcome is the number of correct answers for both categories combined.

The Automatic Picture-Naming test and the Automatic Color-Naming test of the Assessment Battery Sahtil (Sahtil, 2002) were used to measure ability in automatic naming. The automatic picture-naming test consists of 21 pictures that the child is requested to identify as quickly as possible. The outcome is the number of correct answers and the time needed for execution. The automatic color-naming consists of 21 colors with the child requested to name all the colors as quickly as possible. The outcome is the time needed for execution.

The Automatic Digit Naming of the Assessment Battery "Aleph-Taph" (Shany et al., 2005) was used to measure the ability of automatic digit naming. The child had to name 50 digits as fast as possible. The outcome is the executive time.

The Phonological Awareness test of the Assessment Battery Sahtil (Sahtil, 2002) was used to measure phonological awareness. The child had to repeat the first phonemic sound of a nonword. The stimuli were 16 non-words. The outcome is the number of correct answers.

The motor protocol included the following tests:

The Test of Gross Motor Development (TGMD) (Ulrich, 1985 ) was developed to score objectively the quality and quantity of movement in children. It can be used to assess changes as a function of increasing age, experience, instruction or intervention. We used the Israeli version (Hotzler, 1995a, 1995b). The test includes locomotion and object-control abilities. The locomotion part consists of four consecutive items: running, horizontal jumping, sliding and galloping. The object-control subtest consists of four consecutive items: catching, kicking, bouncing and overhand throwing. All data collection was con- ducted in the kindergarten facility. Prior to testing, an accurate demonstration and verbal description of the skill were provided to the child by an experienced adult. The child was given one practice trial to insure that the child understood what to do. If the child did not appear to understand the task or had not performed correctly in the practice trial, additional demonstration and instructions were provided by the experienced adult. Each child then performed three trials for each gross motor skill; first, all the locomotion subtest abilities and then all the object-control abilities. When the performance was correct, a score of 1 was marked; incorrect performances were scored 0 . The sum of both performances represents the final score for each item. The outcome is the score for each part.

Tests of fine motor skills:

Bead-threading test (Fawcett \& Nicolson, 1996): the child had to thread 15 beads as quickly as possible. The outcome was the total time taken, and was assessed twice.

Finger-to-thumb test (Dow \& Moruzzi, 1958): the child placed the index finger of one hand onto the thumb of the other hand and vice-versa. Then, keeping the top thumb and finger together, the child rotated one hand clockwise and the other anti-clockwise until the finger and thumb touched again, and so on. The task was demonstrated and subjects trained until they completed the movement fluently five times. They were then asked to perform ten such movements as quickly as possible. The outcome was the time taken for ten movements, and was assessed twice.

Repetitive finger tapping (Denckla et al., 1985) the children were asked to press repeatedly and as fast as possible a button on a response box with the index finger for $1 \mathrm{~min}$. all presses were recorded and the outcome is the average duration between two presses, the number of presses and standard deviation.

Time estimation included the following test:

The time estimation test was inspired by the test of Nicolson et al. (1995), which was itself inspired by Ivry \& Keele (1989). In each time-estimation trial, two tones were presented successively, and the task was to say whether the second tone was longer or shorter than the first one. The standard stimulus, always presented first, was a 1200 ms-long pure tone of frequency $392 \mathrm{~Hz}$. Fifteen comparison tones had respective durations of 400, 700, 800, 900, 950, 1000, 1050, 1200, 1350, 1450, 1500, 1600,1700 and $2000 \mathrm{~ms}$. The two tones were separated by a 1000-ms silence interval. Each trial was repeated twice, amounting to 30 test trials presented in a random order. The test block was preceded by a practice block of eight trials (using only the eight extreme comparison tones), during which feedback was provided. No feedback was provided during the test block. The stimuli were presented by a computer through headphones at about $75 \mathrm{~dB}$ SPL. After each pair of sounds, subjects had to say whether the second one was longer or shorter than the first one. The outcome is the number of correct answers.

\section{Data Analysis}

The groups were compared on background characteristics. The AMA group and OLMA group were $51.6 \%$ and $53.5 \%$ female, respectively, while the NMA group was $54.5 \%$ male. No significant differences were found between the groups with regard to age and Raven colored progressive matrices score (Raven, 1965) at baseline (see Table 1). 
Table 1.

Sample characteristics.

\begin{tabular}{ccccc}
\hline$F_{(1,91)}$ & $\begin{array}{c}\text { NMA } \\
(\mathrm{n}=22) \\
\mathrm{M}(\mathrm{SD})\end{array}$ & $\begin{array}{c}\text { OLMA } \\
(\mathrm{n}=41) \\
\mathrm{M}(\mathrm{SD})\end{array}$ & $\begin{array}{c}\text { AMA } \\
(\mathrm{n}=31) \\
\mathrm{M}(\mathrm{SD})\end{array}$ & \\
\hline 0.18 & $53.5(7.5)$ & $57.1(8.5)$ & $57.2(7.8)$ & $\begin{array}{c}\text { Chronological } \\
\text { age (months) }\end{array}$ \\
0.61 & $13(2.89)$ & $13.56(3.12)$ & $12.87(3.24)$ & $\begin{array}{c}\text { Raven score } \\
\text { at baseline }\end{array}$ \\
\hline
\end{tabular}

\section{Results}

Do the changes in the fine motor and time estimation abilities mediate the effect study group on the gross motor abilities?

In this section, we examined whether the change in the fine motor abilities and time estimation ability mediated the effect of study groups (AMA, OLMA, and NMA) on gross motor abilities (locomotion and object control). To this end, we employed mediation analyses by Preacher and Hayes's (2008) procedure. This procedure follows Baron and Kenny’s (1986) 4-step method. The progression from one step to the next is contingent on obtaining significant results in the preceding step. In the first step, we examined whether study group (X; the predictor) predicts the change in the fine motor abilities and time estimation ability ( $\mathrm{M}$; the mediators). In the second step, we examined whether the change in the Fine motor abilities and time estimation ability predict the change in gross motor abilities (Y; the outcomes) while controlling for the effect of the study group. In the third step, we examined whether the mediation paths from the study group via the change in the fine motor skills and time estimation ability to the change in gross motor abilities were significant. A significant bias-corrected bootstrap analysis would support mediation. Finally, in the fourth step, we examined whether the direct links from study group to the change in gross motor abilities remained significant while controlling for the change in the fine motor abilities and time estimation ability. A significant direct link would support partial mediation, whereas a non-significant link would support full mediation. In the present analyses, we forgo Baron and Kenny's (1986) traditional first step in which one needs to establish a significant direct link from the predictor to the outcome variable as recommended by Preacher and colleagues (2010) and several other scholars (e.g., Shrout \& Bolger, 2002; MacKinnon, Krull, \& Lockwood, 2000). Step I. To examine whether study group predicts the change in the fine motor abilities and time estimation ability, we first effect-coded the study group variable. This coding enabled us to compare the effect of the AMA group (coded 1) with those of the OLMA group (coded -1 ) and NMA (coded -1). Unstandardized regression coefficients are presented in Figure 1. The analyses revealed that the AMA group was related with a shorter tapping average duration between two presses and with a better time estimation than the NMA group. AMA group was also related with a quicker completion of the beading task and with a better time estimation than the OLMA group. Therefore, we continue to assess the mediation processes only via these Fine motor skills and time estimation ability. Step II. Unstandardized regression coefficients are presented in Table $\mathbf{2}$. The analyses revealed that the quicker the completion of the beading task, the better the locomotion, but not the object control ability. This effect was significant above and beyond the contribution of the study group to the prediction. Steps III to IV. The bias-corrected bootstrap

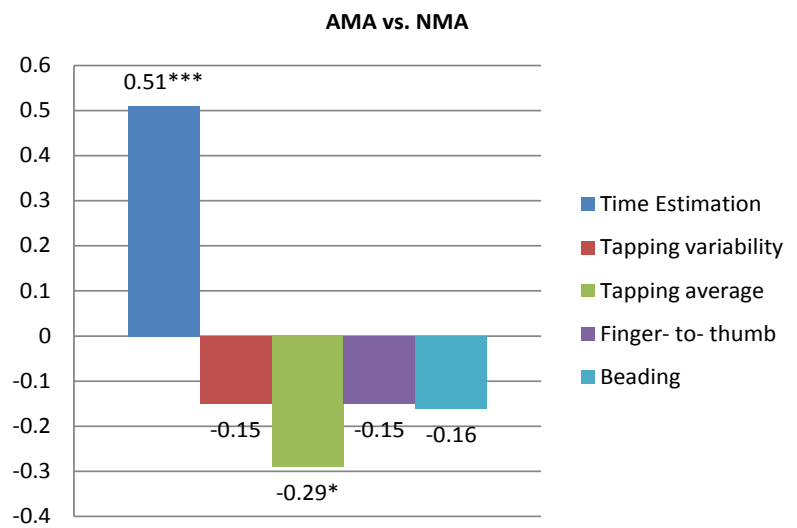

AMA vs. OLMA

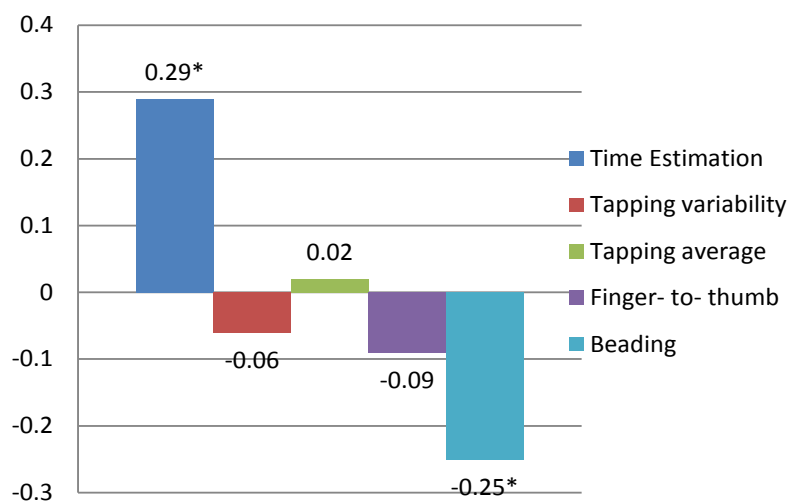

Figure 1.

Unstandardized regression coefficients for predicting the change in the fine motor abilities and time estimation ability by study group. Note: ${ }^{*} p$ $<.05, * * * p<.001$.

Table 2.

Unstandardized regression coefficients for predicting the change in the motoric-related abilities by the fine motor abilities and time estimation ability and study group.

\begin{tabular}{ccc}
\hline Object control & Locomotion & \\
\hline-.08 & $-.23^{*}$ & Beading task \\
-.04 & -.04 & Finger-to-thumb \\
-.11 & -.07 & Tapping average \\
.05 & .01 & Tapping variability \\
.15 & .12 & Time estimation \\
$.25^{*}$ & .12 & AMA vs. NMA \\
$.45^{* * *}$ & $.54^{* * *}$ & AMA vs. OLMA \\
\hline
\end{tabular}

Note: $* p<.05, * * * p<.001$.

analysis revealed that the mediation path from the AMA (verses the OLMA) via the time to complete the beading task to participants' locomotion was significant: the $95 \%$ confidence interval (CI) did not include the value zero (i.e., no effect), CI .01 to .15. In addition, as can be seen in Table 2, the link between study group and participants' locomotion remained significant after 
the inclusion of the fine motor abilities and time estimation ability. Thus, the mediation path was only partial. Figure 2 presents the diagram of the mediating model between AMA (verses the OLMA) via time to complete the beading task to participants' locomotion abilities.

Do the changes in the fine motor and time estimation abilities mediate the effect study group on the language abilities? In this section, we examined whether the change in the fine motor abilities and time estimation mediated the effect of study groups (AMA, OLMA, and NMA) on linguistic abilities (language fluency, object naming time, color naming time, digit naming time, phonological awareness). To this end, we employed mediation analyses by Preacher and Hayes's (2008) procedure, as in our first research question. Step I. To examine whether study group predicts the change in the fine motor abilities and time estimation ability, we used the effect-coding that compare the effect of the AMA group (coded 1) with those of the OLMA group (coded -1) and NMA (coded -1). Unstandardized regression coefficients are presented in Figure 1. The analyses revealed that the AMA group was related with a quicker tapping time and with a better time estimation than the NMA group. AMA group was also related with a quicker completion of the beading task and with a better time estimation than the OLMA group. Therefore, we continue to assess the mediation processes only via these fine motor abilities and time estimation ability. Step II. Unstandardized regression coeffi-
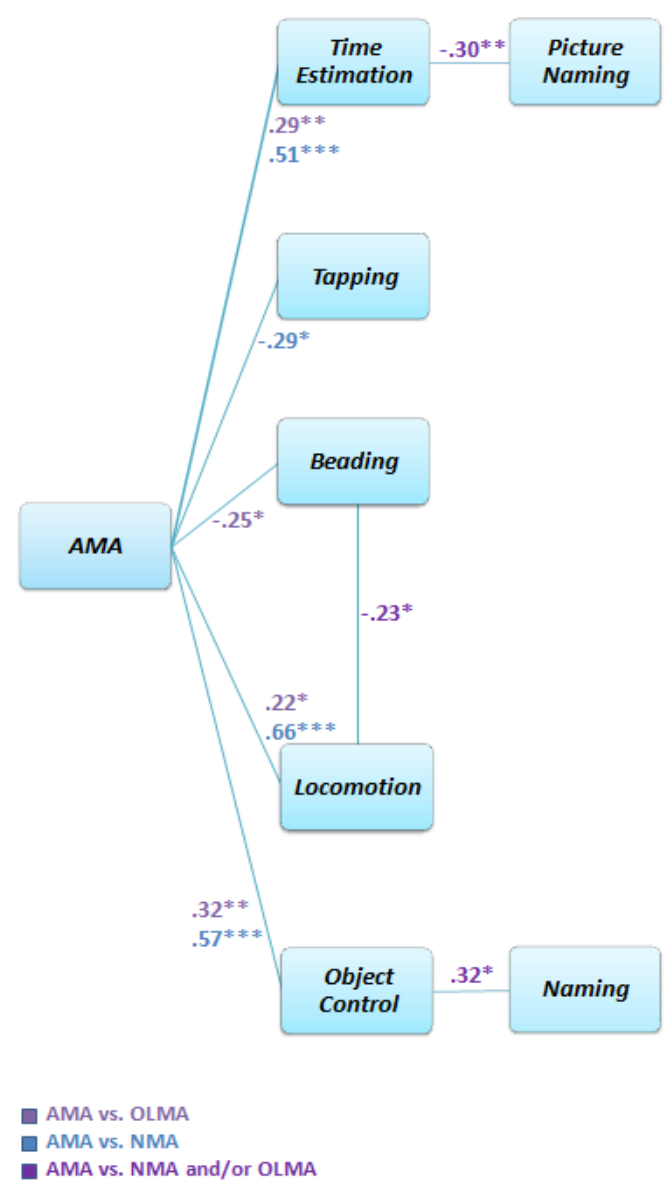

Figure 2.

Conceptual diagram of the mediating models. cients are presented in Table 3 . The analyses revealed that an improvement in the time taken to complete the finger-to-toe task was linked with an improvement in the phonological awareness score. Nevertheless, because study group did not predict the performance in the finger-to-toe task, mediation processes could not have occurred. Conversely, an improvement in the time estimation ability was related with an improvement in the time taken to complete the object naming task. The other paths were not significant. Steps III to IV. Bias-corrected boot-strap analyses revealed that the mediation paths from the AMA group (verses the OLMA and NMA) via the ability to assess time to participants' object naming time were significant: the 95\% confidence intervals (CI) did not include the value zero, CI -.21 to -.03 for NMA, and CI -.32 to -.05 for OLMA. In addition, as can be seen in Table 3, the link between study group and participants' object naming time was not significant after the inclusion of the Cerebellum related abilities. Thus, the time estimation ability fully mediated these paths. Figure 2 presents the diagram of the mediating model between AMA (verses the OLMA training and/or NMA group) via time estimation ability to participants' object naming ability.

Does the change in the gross motor abilities mediate the effect of study group on the linguistic abilities?

In this section, we examined whether the change in the gross motor abilities mediated the effect of study groups (AMA, OLMA, and NMA) on linguistic abilities (language fluency, object naming time, color naming time, digit naming time, phonological awareness). To this end, we employed mediation analyses by Preacher and Hayes's (2008) procedure, as in the first research question. Step I. To examine whether study group predicts the change in the gross motor abilities, we first effectcoded the study group variable. This coding enabled us to compare the effect of the AMA (coded 1) with those of the OLMA (coded -1 ) and NMA (coded -1 ). Unstandardized regression coefficients are presented in Figure 3. The analyses revealed that the AMA was related with a better locomotion and object control abilities than both the NMA and OLMA conditions. Therefore, we continue to assess the mediation processes via all of the gross motor abilities. Step II. Unstandardized regression coefficients are presented in Table $\mathbf{4}$ for linguistic abilities. The analyses revealed that better object control abilities were linked with a quicker naming ability. This effect was significant above and beyond the contribution of the study group to the prediction.

Steps III to IV. The bias-corrected bootstrap analyses revealed that the mediation paths from the AMA (verses the OLMA training and/or NMA group) via object control abilities to participants' overall naming score (95\% CI .06, .45 for AMA vs. NMA, 95\% CI .03, .22 for AMA vs. OLMA) were significant. In addition, as can be seen in Table 4, the path between study group and participants' overall naming score remained significant after the inclusion of the gross motor abilities, the thus the motor-related abilities only partially mediated this path. Figure 2 presents the diagram of the mediating model between AMA (verses the OLMA training and/or NMA group) via object control abilities to participants' overall naming ability.

\section{Discussion}

The aim of this study was to investigate the effects of AMA on motor and language abilities, as well as to examine whether the change in the fine motor abilities and time estimation ability 
Table 3.

Unstandardized regression coefficients for predicting the change in the linguistic abilities by the fine motor abilities and time estimation ability and study group.

\begin{tabular}{cccccc}
\hline Phonological Awareness & Digit Naming & Color Naming & Object Naming & Language Fluency & \\
\hline-.09 & -.02 & .15 & .01 & .05 & Beading \\
$-.23^{*}$ & .15 & $.36^{* *}$ & $.28^{* *}$ & .02 & Finger-to-toe \\
.02 & .06 & .02 & -.13 & .02 & Tapping average \\
.07 & -.04 & .10 & .13 & -.08 & Tapping variability \\
-.15 & -.19 & -.13 & $-.30^{* *}$ & .01 & .02 \\
-.08 & -.13 & -.06 & .05 & .14 & Time Estimation \\
.20 & -.25 & -.06 & .04 & AMA vs. NMA & AMA vs. OLMA \\
\hline
\end{tabular}

Note: ${ }^{*} p<.05, * * * p<.001$
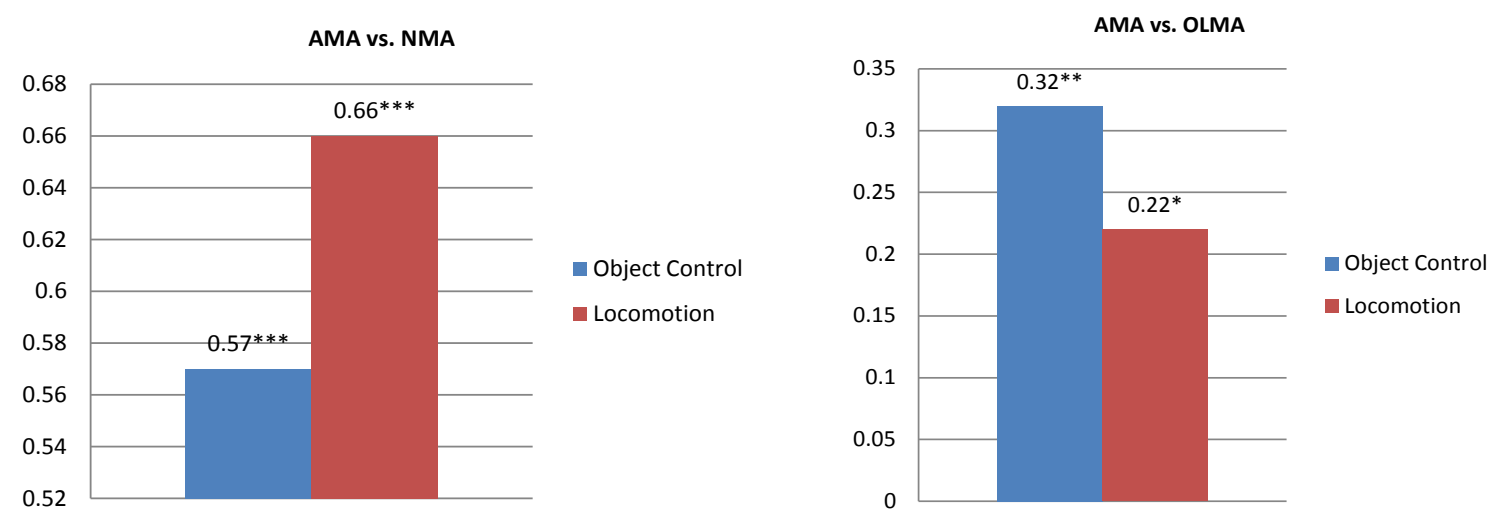

Figure 3.

Unstandardized regression coefficients for predicting the change in the motor-related abilities by study group. Note: ${ }^{*} p<.05$, ${ }^{* *} p$ $<.01, * * * p<.001$.

Table 4.

Unstandardized regression coefficients for predicting the change in the linguistic-related abilities by the gross motor abilities and study group.

\begin{tabular}{ccccccc}
\hline Phonological Awareness & Naming & Digit Naming & Color Naming & Object Naming & Language Fluency & Locomotion \\
\hline-.11 & -.04 & -.19 & -.17 & -.18 & -.02 & Object Control \\
.13 & $.32 *$ & -.24 & .08 & -.06 & -.05 & .03 \\
.16 & -.12 & -.16 & -.16 & -.03 & .03 & AMA vs. NMA \\
-.10 & $-.25 *$ & -.06 & -.16 & .03 & AMA vs. OLMA \\
\hline
\end{tabular}

Note: ${ }^{*} p<.05, * * * p<.001$.

can explain change in language abilities in children. To this aim, we examined 94 four- to six-year-old children attending a normal kindergarten. To our knowledge, this is study the first to examine the extent to which cerebellum-related abilities such as gross motor, fine motor abilities and time estimation ability may be mediator in the relationship between language aspects and AMA.

First, we found that the AMA group was related with better gross motor abilities than both the NMA and OLMA conditions. in contrast to Becker (2009: p. 865), who claimed that it is unlikely that aquatic training can substantially improve dryland performance in adults (Killgore, Wilcox, Caster, \& Wood, 2006; Robinson, Devor, Merrick, \& Buckworth, 2004), our results suggest that AMA during early childhood significantly improved gross motor abilities as compared to NMA and OLMA. We suggest that the unique combinations of multisensory stimuli that characterize the aquatic environment and high neuroplasticity accessible during early childhood are responsible for this difference. The aquatic environment activates a combination of the vestibular system and the tactile system, due to characteristics of water such as density, hydrostatic pressure, buoyancy, etc. The physical conditions of the aquatic environment allow training on different depths with different gravity. Moreover, the aquatic environment provides three dimensions of movement rather than the two present on land. This has probably resulted in more and/or new sensory information during 
AMA, which could account for the difference between the OLMA and AMA groups. The current results of enhancing gross motor-related abilities, are in line with previous studies which reported a similar enhancement, which was claimed to be mediated by increased cortical activation motor areas which was induced by water immersion (Sato et al., 2012).

Second, AMA was related with a shorter tapping average duration between two presses than the NMA group. AMA group was also related with a quicker completion of the beading task than the OLMA group. The development of the human body follows a proximo-distal and cephalo-caudal direction (Sharma, 2005). Thus, children who evidence greater improvement in the gross motor abilities, in the AMA group, may have greater capacity for some fine motor abilities, as evidenced by the scores in bead-threading and the tapping task which are a fine motor task. A possible mediating mechanism for our finding regarding to the motor abilities and the time estimation ability might be increased cerebellar activity, as will be discussed below.

AMA provides multisensory stimulation combining these three sensory systems: the vestibular, the proprioception and the tactile. Immersion increases the proprioceptive input and sensory feedback to the immersed body (Roth et al., 2006). The vestibular system is in the inner ear and reacts to head movements relative to gravity, and is connected to the cerebrum via the brain stem and cerebellum. The system operates in integration with the proprioceptive system and produces the sense of balance and stability. The vestibular system influences regulation of muscle tension, body-movement coordination, and control of eye movements which ensure a stable field of vision while moving (Bundy \& Murray, 2002). The proprioceptive system refers to the sensation provided by muscles, ligaments and joints, and is created as a result of body movement.

Proprioception allows ongoing awareness of posture and body movements in space, and the rhythm and timing of these movements (Williamson \& Anzalone, 2001). Thus, it is a system providing external feedback to the cerebellum, allowing regulation of motor activity. The tactile system has receptors in the skin, serving as a mediator between self and environment (Williamson \& Anzalone, 2001). Thus, the tactile system provides the cerebellum with external feedback, allowing improved reaction time and precision of movement via the cerebellum.

Third, AMA was related with a better time estimation than both the NMA and OLMA conditions. Timing-processing is divided into two separate aspects: motor timing, which refers to the timing aspects of motor, speech and cognitive acts; and time perception, which refers to the discriminative aspects of cognitive time management, such as the ability to estimate temporal delays (Fuster, 1990). The intermediate cerebellum, through its direct connections with the motor system, mediates the motor aspects of timing, while the lateral cerebellar hemispheres and their output nuclei mediate the cognitive or perceptual aspects of timing through their connections with the fronto-parietal association cortex (Middleton \& Strick, 1994). However, functional neuroimaging studies showed activation of both the medial and the lateral zones of the cerebellar cortex during tasks requiring the precise representation of temporal information (Kawashima et al., 2000; Ramnani \& Passingham, 2001; Harrington et al., 2004). Thus, it is still unclear if the cerebellar system mediates time-perception independently from motor behavior or other cognitive functions. Our findings suggest that time-estimation is associated with motor activities and motor behavior. However, how these results relate to cerebellar activation and neuroplasticity requires additional investigation.

Forth, we did not find differences between the study groups in language abilities. Interestingly, we confirmed association between motor activities in gross motor abilities aspects, but only partially in fine motor aspects. Previous studies found that by kindergarten, fine motor tasks are better predictors of reading achievement than gross motor tasks (Wolff, Gunnoe, \& Cohen, 1985). In longitudinal study, children with composite gross and fine motor abilities in preschool attained higher levels of third-grade reading achievement (McPhillips \& Jordan-Black, 2007). Moreover, Grissmer et al. (2010) found that gross motor abilities did not predict achievement, but fine motor abilities did predict later achievement in math and reading. It seems that fine motor, rather than gross motor abilities are more significant in predicting language abilities. Thus, it seems reasonable to hypothesize that our results about no differences between the three study groups in linguistics abilities could be due to the partially differences in fine motor aspects.

Fifth, an improvement in the time estimation ability was related with an improvement in the time taken to complete the object naming task. In addition, better object control abilities were linked with a quicker naming ability. Appropriate naming development is essential for normal reading acquisition (Norton \& Wolf, 2012). In fact, difficulties in naming ability have been found to be the most significant precursor of developmental reading disability (Georgiou, Parrila, \& Liao, 2008, Tan et al., 2005). Reading has been reported as a sensitive process (Breznitz, 2006), which can be affected by timing abilities. It has been proposed that a lack of well-timed, automated, motor abilities inhibits the normal development of articulator gestures (Nicolson, Fawcett, \& Dean, 2001). Therefore, children with dyslexia have been found to be slower in the automatic temporal abilities (Overy, Nicolson, Fawcett, \& Clarke, 2003). RamTzur et al. (2006) found longer saccadic reaction times in students with reading disabilities, and suggested some theories for explaining the possible mechanism of these findings. A common element of these theories is the conviction that timing abilities are a fundamental problem area in dyslexia. The cerebellum has a function in the neural mechanism of timing, and this might explain our findings relating time-estimation to colornaming ability. Many neuroimaging studies, most of which are on normal adults (Desmond et al., 1997; Mechelli Gorno-Tempini \& Price, 2003), support the role of the cerebellum in language abilities. The findings of the current study support the role of neurobiological mechanisms in the theory of the relationship between language abilities and motor performances. Finally, we have demonstrated that the mediation paths from the AMA group (versus the OLMA and NMA) via the ability to assess time to participants' automatic picture-naming were significant. In addition, the link between AMA group and participants' automatic picture-naming was not significant after the inclusion of the time-estimation ability. Thus, the time-estimation ability fully mediated this path. Moreover, we have demonstrated that the mediation path from the AMA (verses the OLMA training and/or NMA group) via object control abilities to participants' overall naming score (including sum of the object naming and color naming scores) was significant. In addition, the path between study group and participants' overall naming score remained significant after the inclusion of the motor-related abilities, thus the motor-related abilities only partially mediated this path. These mediation paths suggest the 
positive effect of AMA on language abilities. It is important to remember that motor abilities are also cerebellum-related abilities. These novel findings shed light on the normal development of the neural network controlling reading-related abilities, which emphasize the importance of the cerebellar activity. Moreover, intervention that enhances functions traditionally related to cerebellum activity leads to improvements in automatic naming ability.

\section{Study Limitations}

Up to now, there has been very little research in the field of AMA, especially in regard to the contribution of aquatic activities to areas of functioning that are not physiological or motor-related. The current exploratory study provides a neurobiological hypothesis for the relationship between an aquatic environment and language processes. This is a new concept for research, and one having great importance for developing our understanding of the contribution of aquatic activities. Nevertheless, the study has limitations that should be acknowledged. First, the small sample size limited the power of the study and prevents further sub analyses, such as examination of family history of learning disabilities. Second, we are aware of the potential differences between various types of motor and nonmotor activities that are non-aquatic and that the allocation of the groups was not random. However, this is a preliminary research aimed to examine the relationship between AMA and language abilities in normal population during early childhood, as the research related to AMA in this population is scarce. Third, we used gross motor, fine motor and time estimation test as "cerebellum-related" abilities. The claim should be accompanied by the examination of exercise on brain morphology and internal connectivity (MRI or TDI). Further research is needed to conduct a study that includes this possibility for validating our results. We are currently examining working in this direction.

\section{Conclusion}

In conclusion, data from our study supported the "cerebellar deficit hypothesis of dyslexia” (Nicolson et al., 2001) suggesting that motor and non motor cerebellar-related abilities are associated with naming abilities. In addition, time-estimation ability moderated the association between AMA and children's picture naming ability, while object control abilities moderated the association between aquatic motor activities and children's overall naming score, suggesting the positive effect of AMA on language abilities. Together, the study may contribute to the understanding of the possibilities of different motor intervention in different environments. The combination of the advantages of an aquatic environment for children may provide useful knowledge for physical-education teachers and could be utilized in the development of motor interventions for preschool children.

According to our study, early aquatic motor intervention may help reduce early motor difficulties, thereby possibly preventing additional motor disorders which can lead to associated educational problems. Thus, our findings might be the basis for new interventions for naming-related disabilities, such as dyslexia.

\section{Acknowledgements}

The results of this research are part of Michal Nissim's thesis,
Bar-Ilan University in partial fulfillment of the requirements toward her Ph.D. degree.

Michal Nissim is grateful to the Azrieli Foundation for the award of an Azrieli Fellowship.

The authors also wish to thank The Ministry of Education's Chief Scientist in Israel for the approval and support in conducting this research.

\section{REFERENCES}

Ahrendt, L. (1999). Influence of water programs on infants motor development during the first year of life under consideration of their mothers, physical concept. In the 5th International Aquaic Education Conference, Toulouse, 21-23 October 1999. Compte Rendu FAAEL.

Baron, R., \& Kenny, D. A. (1986). The moderator-mediator variable distinction in social psychological research: Conceptual, strategic, and statistical considerations. Journal of Personality and Social Psychology, 51, 1173-1182.

http://dx.doi.org/10.1037/0022-3514.51.6.1173

Becker, B. E., \& Cole, A. J. (1997). Comprehensive aquatic therapy. Boston: Butterworth-Heinemann.

Becker, B. E. (2009). Aquatic therapy: Scientific foundations and clinical rehabilitation applications. American Academy of Physical Medicine and Rehabilitation, 1, 859-872.

Ben-Soussan, T. D., Glicksohn, J., Goldstein, A., Berkovich-Ohana, A., \& Donchin, O. (2013). Into the Square and out of the box: The effects of quadrato motor training on creativity and alpha coherence. PloSone, 8, e55023. http://dx.doi.org/10.1371/journal.pone.0055023

Breznitz, Z. (2006). Fluency in reading: Synchronization of processes. Hillsdale, NJ: Lawrence Erlbaum Associates.

Blakemore, S. J., \& Frith, U. (2005). The learning brain: Lessons for education. Oxford: Blackwell.

Bundy, A. C., \& Murray, A. E. (2002). Sensory integration: A. Jean Ayres' theory revisited. In A. C. Bundy, S. J. Lane, \& E. A. Murray (Eds.), Sensory integration: Theory and practice (2nd ed., pp. 3-33). Philadelphia: F. A. Davis.

Campion, M. R. (1997). Hydrotherapy. Oxford: ButterWarth-Heinemann.

Cragg, S., \& Cameron, C. (2006). Physical activity of Canadian youth-An analysis of 2002 health behaviour in school-aged children data. Canadian Fitness and Lifestyle Research Institute. Ottawa: Ontario.

Denckla, M. B., Rudel, R. G., Chapman, C., \& Krieger, J. (1985). Motor proficiency in dyslexic children with and without attentional disorders. Archives of Neurology, 42, 228-231. http://dx.doi.org/10.1001/archneur.1985.04060030042008

Desmond, J. E., Gabrieli, J. D. E., Wagner, A. D., Ginier, B. L., \& Glover, G. H. (1997). Lobular patterns of cerebellar activation of verbal working-memory and finger-tapping tasks as revealed by functional MRI. Journal of Neuroscience, 17, 9675-9685.

Devereux, K., Robertson, D., \& Briffa, N. K. (2005). Effects of a water-based program on women 65 years and over: A randomized controlled trial. Australian Journal of Physiotherapy, 51, 102-108. http://dx.doi.org/10.1016/S0004-9514(05)70038-6

Dow, R., \& Moruzzi, G. (1958). The physiology and pathology of the cerebellum. Minneapolis, MN: University of Minnesota Press.

Fawcett, A., \& Nicolson, R. (1996). The dyslexia screening test. London: The Psychological Corporation.

Fuster, J. M. (1990). Prefrontal cortex and the bridging of temporal gaps in the perception-action cycle. Ann N Y Acad Sci, 608, 318-329. http://dx.doi.org/10.1111/j.1749-6632.1990.tb48901.x

Georgiou, G. K., Parrila, R., \& Liao, C. H. (2008). Rapid naming speed and reading across languages that vary in orthographic consistency. Read. Writ, 21, 885-903. http://dx.doi.org/10.1007/s11145-007-9096-4

Grissmer, D., Grimm, K. J., Aiyer, S. M., Murrah, W. M., \& Steele, J. S. (2010). Fine motor skills and early comprehension of the world: Two new school readiness indicators. Developmental Psychology, 46, 1008-1017. http://dx.doi.org/10.1037/a0020104 
Grossman, A. W., Churchill, J. D., Bates, K. E., Kleim, J. A., \& Greenough, W. T. (2002). A brain adaptation view of plasticity: Is synaptic plasticity an overly limited concept? Prog Brain Res, 138, 91-108. http://dx.doi.org/10.1016/S0079-6123(02)38073-7

Hannaford, C. (2005). Smart moves: Why learning is not all in your head (2nd ed.). Great River Books.

Harrington, D. L., \& Haaland, K. Y. (1999). Neural underpinnings of temporal processing: A review of focal lesion, pharmacological, and functional imaging research. Rev Neurosci, 10, 91-116. http://dx.doi.org/10.1515/REVNEURO.1999.10.2.91

Harrington, D. L., Boyd, L. A., Mayer, A. R., Sheltraw, D. M., Lee, R. R., Huang, M., \& Rao, S. M. (2004). Neural representation of interval encoding and decision making. Brain Res Cogn Brain Res, 21, 193-205. http://dx.doi.org/10.1016/j.cogbrainres.2004.01.010

Heckman, J. J., Stixrud, J., \& Urzua, S. (2006). The effects of cognitive and noncognitive abilities on labor market outcomes and social behavior. Journal of Labor Economics, 24, 411-482. http://dx.doi.org/10.1086/504455

Hill, E. L. (2001). Non-specific nature of specific language impairment: A review of the literature with regard to concomitant motor impairments. International Journal of Language \& Communication Disorders, 36, 149-171. http://dx.doi.org/10.1080/13682820010019874

Holzer, I. (1996). Assessment of motor abilities in school-age children: Theoretical aspects. Part 1. Journal of Sports \& Physical Education, 1, 15-18. (Hebrew).

Holzer, I. (1996). Assessment of motor abilities in school-age children: Recommendations for Grades 1-4. Journal of Sports \& Physical Education, 2, 22-25. (Hebrew).

Hurks, P., Vles, J., Hendriksen, J., Kalff, A., Feron, F., Kroes, M. et al. (2006). Semantic category fluency versus initial letter fluency over 60 seconds as a measure of automatic and controlled processing in healthy school-aged children. Journal of Clinical \& Experimental Neuropsychology, 28, 684-695. http://dx.doi.org/10.1080/13803390590954191

Ivry, R. B., Keele, S. W., \& Diener, H. C. (1988). Dissociation of the lateral and medial cerebellum in movement timing and movement execution. Exp Brain Res, 73, 167-180. http://dx.doi.org/10.1007/BF00279670

Ivry, R. B., \& Keele, S. W. (1989). Timing functions of the cerebellum. Journal of Cognitive Neuroscience, 1, 136-152. http://dx.doi.org/10.1162/jocn.1989.1.2.136

Ivry, R. B., \& Diener, H. C. (1991). Impaired velocity perception in patients with lesions of cerebellum. J Cogn Neurosci, 3, 355-366. http://dx.doi.org/10.1162/jocn.1991.3.4.355

Kave, G. (2006). The Development of naming and word fluency: Evidence from Hebrew-speaking children between Ages 8 and 17. Developmental Neuropsychology, 29, 493-508. http://dx.doi.org/10.1207/s15326942dn2903_7

Kawashima, R., Okuda, J., Umetsu, A., Sugiura, M., Inoue, K., Suzuki, K. et al. (2000). Human cerebellum plays an important role in memory-timed finger movement: an fMRI study. J Neurophysiol, 83, 10791087.

Killgore, G. L., Wilcox, A. R., Caster, B. L., \& Wood, T. M. (2006). A lower-extremities kinematic comparison of deep-water running styles and treadmill running. J Strength Cond Res, 20, 919-927.

Lakoff, G., \& Johnson, M. (1999). Philosophy in the flesh: The embodied mind and its challenges to western thought. New York: Basic Books.

Losse, A., Henderson, S. E., Elliman, D., Hall, D., Knight, E., \& Jongmans, M. (1991). Clumsiness in children: Do they grow out of it? A 10-year follow-up study. Developmental Medicine and Child Neurology, 33, 55-68. http://dx.doi.org/10.1111/j.1469-8749.1991.tb14785.x

MacKinnon, D. P., Krull, J. L., \& Lockwood, C. M. (2000). Equivalence of the mediation, confounding and suppression effect. Prevention Science, 1, 173-181. http://dx.doi.org/10.1023/A:1026595011371

McPhillips, M., \& Jordan-Black, J. A. (2007). Primary reflex persistence in children with reading difficulties (dyslexia): A cross-sectional study. Neuropsychologia, 45, 748-754. http://dx.doi.org/10.1016/j.neuropsychologia.2006.08.005

Mechelli, A., Gorno-Tempini, M. L., \& Price, C. J. (2003). Neuroimaging studies of word and pseudoword reading: Consistencies, inconsistencies, and limitations. Journal of Cognitive Neuroscience, 15, 260-271. http://dx.doi.org/10.1162/089892903321208196

Middleton, F. A., \& Strick, P. L. (1994). Anatomical evidence for cerebellar and basal ganglia involvement in higher cognitive function. Science, 266, 458-461. http://dx.doi.org/10.1126/science.7939688

Murray, G. K., Jones, P. B., Kuh, D., \& Richards, M. (2007). Infant developmental milestones and subsequent cognitive function. Ann Neurol, 62, 128-136. http://dx.doi.org/10.1002/ana.21120

Nicolson, R. I., Fawcett, A. J., \& Dean, P. (1995). Time estimation deficits in developmental dyslexia: Evidence of cerebellar involvement. Proc. R. Soc. Lond B Biol. Sci., 259, 43-47. http://dx.doi.org/10.1098/rspb.1995.0007

Nicolson, R. I., Fawcett, A. J., \& Dean, P. (2001). Dyslexia, development and the cerebellum. Trends Neurosci, 24, 515-516. http://dx.doi.org/10.1016/S0166-2236(00)01923-8

Norton, E. S., \& Wolf, M. (2012). Rapid automatized naming (RAN) and reading fluency: Implications for understanding and treatment of reading disabilities. Annual Review of Psychology, 63, 427-452. http://dx.doi.org/10.1146/annurev-psych-120710-100431

Overy, K., Nicolson, R. I., Fawcett, A. J., \& Clarke, E. F. (2003). Dyslexia and music: Measuring musical timing skills. Dyslexia, 9, 18-36. http://dx.doi.org/10.1002/dys.233

Preacher, K. J., \& Hayes, A. F. (2008). Asymptotic and resampling strategies for assessing and comparing indirect effects in multiple mediator models. Behavior Research Methods, 40, 879-891. http://dx.doi.org/10.3758/BRM.40.3.879

Preacher, K. J., Zyphur, M. J., \& Zhang, Z. (2010). A general multilevel SEM framework for assessing multilevel mediation. Psychological Methods, 15, 209-233. http://dx.doi.org/10.1037/a0020141

Ramnani, N., \& Passingham, R. E. (2001). Changes in the human brain during rhythm learning. J Cogn Neurosci, 13, 952-966. http://dx.doi.org/10.1162/089892901753165863

Ram-Tsur, R., Faust, M., Caspi, A., Gordon, C. R., \& Zivotofsky, A. Z. (2006). Evidence for ocular-motor deficits in developmental dyslexia: Application of the double-step paradigm. Invest Ophthalmology Visual Science, 47, 4401-4409. http://dx.doi.org/10.1167/iovs.05-1657

Ram-Tsur, R., Faust, M., \& Zivotofsky, A. Z. (2008). Poor performance on serial visual tasks in persons with reading disabilities: Impaired working memory? J Learn Disabil, 41, 437-450. http://dx.doi.org/10.1177/0022219408321141

Raven, J. C. (1965). Guide to using the coloured progressive matrices sets $A, A b, B$. (Revised Order, 1956). London: H.K. Lewis.

Riva, D., Nichelli, F., \& Devoti, M. (2000). Developmental aspects of verbal fluency and confrontation naming in children. Brain and Language, 71, 267-284. http://dx.doi.org/10.1006/brln.1999.2166

Robinson, L. E., Devor, S. T., Merrick, M. A., \& Buckworth, J. (2004). The effects of land vs. aquatic plyometrics on power, torque, velocity, and muscle soreness in women. J Strength Cond Res, 18, 84-91.

Roth, A. E., Miller, M. G., Ricard, M., Ritenour, D., \& Chapman, B. L. (2006). Comparisons of static and dynamic balance following training in aquatic and land environments. Journal of Sport Rehabilitation, 15, 299-311.

Sato, D., Yamashiro, K., Onishi, H., Shimoyama, Y., Yoshida, T., \& Maruyama, A. (2012). The effect of water immersion on short-latency somatosensory evoked potentials in human. BMC Neuroscience, 13, 13-19. http://dx.doi.org/10.1186/1471-2202-13-13

Shany, M., Bahat, A., Lachman, D., Shalem, Z., \& Zeiger, T. (2005). "Aleph-Taph": An assessment system for reading and writing disabilities [in Hebrew]. Tel Aviv, Israel: Yesod.

Sharma, V. K., Das, S., Mondal, S., Goswami, U., \& Gandhi, A. (2005). Effect of sahaj yoga on depressive disorders. Indian J Physiol Pharmacol, 49, 462-468.

Shatil, E. (2002). The Shatil test for the early detection of specific disabilities and of general language impairments in the acquisition of reading and spelling: The comprehensive evaluation [in Hebrew]. Kiryat Bialick, Israel: Ach Books.

Shrout, P. E., \& Bolger, N. (2002). Mediation in experimental and non- 


\section{R. RAM-TSUR ET AL.}

experimental studies: New procedures and recommendations. Psychological Methods, 7, 422-445.

http://dx.doi.org/10.1037/1082-989X.7.4.422

Smith, L. B., \& Thelen, E. (2003). Development as a dynamic system. Trends in Cognitive Sciences, 7, 343-348. http://dx.doi.org/10.1016/S1364-6613(03)00156-6

Stoodley, C. J., \& Stein, J. F. (2011). The cerebellum and dyslexia. Cortex, 47, 101-116. http://dx.doi.org/10.1016/j.cortex.2009.10.005

Strong, W. B., Malina, R. M., Blimkie, C. J., Daniels, S. R., Dishman, R. K., Gutin, B., et al. (2005). Evidence based physical activity for school-age youth. Journal of Pediatrics, 146, 732-737. http://dx.doi.org/10.1016/j.jpeds.2005.01.055

Tan, L. H., Spinks, J. A., Eden, G. F., Perfetti, C. A., \& Siok, W. T. (2005). Reading depends on writing, in Chinese. Proc. Natl. Acad. Sci, 102, 8781-8785. http://dx.doi.org/10.1073/pnas.0503523102

Ulrich, D. A. (1985). Test of gross motor development. Texas: Pro-ED.

Warburton, D. E., Nicol, C. W., \& Bredin, S. S. (2006). Health benefits of physical activity: The evidence. Canadian Medical Association Journal, 174, 801-809. http://dx.doi.org/10.1503/cmaj.051351

Webster, R. I., Majnemer, A., Platt, R. W., \& Shevell, M. I. (2005).
Motor function at school age in children with a preschool diagnosis of developmental language impairment. The Journal of Pediatrics, 146, 80-85. http://dx.doi.org/10.1016/j.jpeds.2004.09.005

Wigfield, A. (1994). Expectancy-value theory of achievement motivation: A developmental perspective. Educational Psychology Review, 6, 49-78. http://dx.doi.org/10.1007/BF02209024

Wigfield, A., \& Eccles, J. S. (2000). Expectancy-value theory of motivation. Contemporary Educational Psychology, 25, 68-81. http://dx.doi.org/10.1006/ceps.1999.1015

Williamson, G. G., \& Anzalone, M. E. (2001). Sensory integration and self-regulation in infants and toddlers: Helping very young children interact with their environment. Washington DC: Zero to Three.

Wolff, P. H., Gunnoe, G., \& Cohen, C. (1985). Neuromotor maturation and psychological performance: A developmental study. Developmental Medicine and Child Neurology, 27, 344-354. http://dx.doi.org/10.1111/j.1469-8749.1985.tb04546.x

Zelazo, R., \& Weiss, M. J. (2006). Infant swimming behaviors: Cognitive control and the influence of experience. Journal of Cognition and Development, 7, 1-25.

http://dx.doi.org/10.1207/s15327647jcd0701_1 